\title{
A Microbiological Study of Acinetobacter baumannii with Special Reference to Multi-Drug Resistance
}

\author{
Amrita Talukdar*, Anahita Bhesania Hodiwala and Revati Sharma \\ Department of Microbiology, MGM Medical College and Hospital, Kamothe, \\ Navi Mumbai, India \\ *Corresponding author
}

\section{A B S T R A C T}

\section{Keywords}

Acinetobacter baumannii, Multi-drug resistance, Modified Hodge Test, CRAB, Metallo- $\beta$ - lactamases

Article Info

Accepted:

10 January 2018

Available Online:

10 February 2018
Acinetobacter calcoaceticus baumannii (ACB) is a significant pathogen in hospitals with a growing incidence of multi-drug resistant (MDR) strains. This was a prospective study carried out on ACB isolates from clinical samples between 2013 and 2015. Anti-microbial susceptibility testing was done by Kirby-Bauer Disk Diffusion method (KBBD) method. CRAB strains were tested by Modified Hodge test (MHT) to detect MBL producers. Of the 190 ACB isolates, 142 (75\%) were MDR strains. 93\% were hospital acquired and 7\% community acquired. MDR was seen only in hospital acquired isolates. Acinetobacter was most commonly isolated from ICU $(51.41 \%)$; followed by medicine ward and surgical wards. $34 \%$ of the isolates were from endotracheal tubes which were followed by sputum $(14 \%)$, pus $(13 \%)$, blood $(10 \%)$, suction catheter $(7 \%)$ and urine $(5 \%)$. The maximum number of isolates was seen in patients above 60 years of age (28.94\%). Among all samples, $120(63 \%)$ were CRAB strains of which 63 out of $120(53 \%)$ were found to be MBL producers by Modified Hodge test (MHT). A high incidence of MDR was seen in ACB from samples of hospitalized patients. MHT is an economical test which can be included in routine testing for detection of MBL phenotypes.

\section{Introduction}

Acinetobacter baumannii is an important nosocomial pathogen ranked second after Pseudomonas aeruginosa among aerobic nonfermentative gram-negative bacilli (Schreckenberger et al., 1999; Simor et al., 2002). It causes respiratory and urinary tract infections, meningitis, endocarditis, burn infections, and wound sepsis, especially in intensive care units (ICUs) (Chastre et al., 2000). A. baumannii infections are often difficult to eradicate due to high-level resistance to many antibiotics as a result of intrinsic and acquired mechanisms (Yong et al., 2003) Carbapenems (e.g., imipenem and meropenem) have become the drugs of choice against Acinetobacter infections in many centers but are being compromised by the emergence of carbapenem-hydrolyzing $\beta$ lactamase (carbapenemase) of molecular classes B and D (Livermore et al., 2002). Therefore studies of epidemiology and antibiotic resistance are necessary to help in treatment of infections. 
The detection of carbapenemase production is complicated because some carbapenemaseproducing isolates demonstrate elevated yet susceptible Carbapenem minimum inhibitory concentration (MIC). CLSI has published guidelines for detection of isolates producing carbapenemase (CLSI document M100).

Various methods like, EDTA disk synergy (EDS) test, MBL E-test, EDTA-based microbiological assay are used for detection of MBLs (Noyal et al., 2009). For isolates that test susceptible to a Carbapenem but demonstrate reduced susceptibility either by disk diffusion or MIC testing, performing a phenotypic test for carbapenemase activity, the Modified Hodge Test (MHT), is recommended (Calfee et al., 2008; Wayne et al., 2009; Deshpande et al., 2006; Siegel et al., 2007).

This study was taken up to isolate and identify the A. baumannii from various clinical samples and to determine their Carbapenemase activity by MHT.

The present study aims at:

To detect the prevalence rate of $A$. calcoaceticus baumannii (ACB) infections from various clinical samples.

To find out the antimicrobial resistance pattern of A. baumannii.

To find the incidence of MBL production amongst CRAB (Carbapenem-resistant Acinetobacter baumannii).

\section{Materials and Methods}

The study was carried out in the Department of Microbiology and MGM Central Research Laboratory at MGM Medical College and Hospital, Kamothe, Navi Mumbai, for 2 years duration (December 2013 to December 2015).
190 Acinetobacter baumannii isolates obtained from various clinical samples including endotracheal tube, sputum, pus, blood, suction catheter tip, tracheostomy tube, urine, tissue and Foley's catheter tip etc. were included in the study. Acinetobacter baumannii were identified using standard microbiological procedures. The Kirby-Bauer Disk Diffusion method (KBBD) was carried out for antimicrobial susceptibility testing as per CLSI guidelines 2014. All Carbapenemresistant Acinetobacter baumannii (CRAB) strains were tested by Modified Hodge test (MHT) for detection of MBL producers.

All the isolates were tested for Carbapenemase production by MHT.

\section{Modified Hodge test}

\section{Procedure}

0.5 McFarland dilution of the E. coli ATCC 25922 in $5 \mathrm{ml}$ of Broth or saline was prepared. A lawn of the 1:10 dilution of $E$. coli ATCC 25922 was streaked on a Mueller Hinton agar plate and allowed to dry for 3-5 minutes. A 10 $\mu \mathrm{g}$ Imipenem, disc was placed in the centre of the plate. In a straight line, test organism from the edge of the disc to the edge of the plate was streaked.

Plates were incubated overnight at $35^{\circ} \mathrm{C} \pm 2^{\circ} \mathrm{C}$ for 16-24 hours. After 16-24 hours of incubation, the plates were examined for a clover leaf-type indentation at the intersection of the test organism and the E. coli 25922, within the zone of inhibition of the Carbapenem susceptibility disc. MHT Positive test has a clover leaf-like indentation of the E. coli 25922 growing along the test organism growth streak within the disc diffusion zone. MHT Negative test has no growth of the E. coli 25922 along the test organism growth streak within the disc diffusion (CDC-Center of disease control). 


\section{Results and Discussion}

In our study, out of the 190 ACB isolates, $142(75 \%)$ were multidrug resistant. $93 \%$ were hospital acquired and only $7 \%$ were community acquired. Among the in-patients, Acinetobacter was most commonly isolated from ICU $(51.41 \%)$ which include medicine ICU (32\%), surgical ICU (9.60\%), neonatal ICU $(9.60 \%)$, followed by medicine ward $(13 \%)$, neurosurgery ward (12\%), general surgery ward $(11 \%)$, orthopaedics ward $(5.64 \%)$ and cardiothoracic ward $(3.38 \%)$. $34 \%$ of the isolates were isolated from endotracheal secretion which were followed by sputum (14\%), pus (13\%), blood $(10 \%)$, suction catheter $(7 \%)$ and urine $(5 \%)$ samples.

MDR was seen only in hospital acquired isolates. Among all samples, 120 (63\%) were CRAB strains of which 63 out of $120(53 \%)$ were found to be MBL producers. The Modified Hodge test (MHT) was used by us to detect carbapenemase activity. It is easily available in clinical microbiology routine settings and recommended by the CLSI for phenotypic detection of carbapenemase. Maximum ACB isolates showed resistance to cephalosporins whereas least resistance was seen to fluoroquinolones.

Mahajan et al., (2012), showed highest isolation being from the ICU $(51.61 \%)$, surgery $(21.5 \%)$, paediatrics $(10.2 \%)$, orthopaedics $(7.5 \%)$ and medicine (5.7\%). In the study done by Prashanth and Badrinath (2006), the highest $(42 \%)$ isolates were from ICU, medicine (37\%), paediatrics (23\%), surgery $(21 \%)$ and orthopaedics $(2.3 \%)$ wards. Also in a study by Jaggi et al., (2012), the proportion of $A$. baumannii isolates was higher in the ICU (76.7\%) as compared to the in-patient wards (18.7\%) and OPD (4.5\%) pointing towards the fact that $A$. baumannii is a predominantly ICU bug. Our result corroborates the fact that a lot of risk factors associated with Acinetobacter infection exist in the ICU like potential environmental reservoirs for A. baumannii, opportunities for cross transmission, sick, immune compromised patients who are colonized, patients having multiple wounds and indwelling devices, heavy use of broad spectrum antibiotics and frequent contamination of the hands of health care workers while patient care.

However some other studies by Lahiri et al., (2004) and Mindolli et al., (2010) showed different results from our study, as they found highest isolation from surgical ward (Table 1 and 2).

In our study the highest number the isolates (34\%) were from endotracheal secretions, followed by sputum (14\%), pus (13\%), blood $(10 \%)$, suction catheter (7\%), tracheostomy tube $(6 \%)$, urine $(5 \%)$, tissues $(4 \%)$, Foley's catheter tip (2\%) etc (Table 3). Peymani et al., (2011) also showed similar findings, where maximum isolates were from ET (37\%). Mindolli et al., (2010) in contrast, found only $3.5 \%$ isolates from ET and a maximum of $29 \%$ from pus samples.

In our study, the maximum no. of isolates were from patients above 60 years of age (28.94\%), followed by $21-30$ years $(17.36 \%)$, $31-40$ years $(14.21 \%)$ and least were from the paediatric age group of 2-10 years of age $(2.10 \%)$. Among (0-1) years age group, maximum isolates $(12.10 \%)$ were seen in new born babies with endotracheal tubes who were all preterm. This showed that presence of endotracheal tubes and preterm birth was predisposing factors for developing ACB infection in neonates (Table 4). Mahajan et al., (2012), found different results where, $10.75 \%$ isolates were isolated in age $<17$ years, $22.58 \%$ in age between $18-35$ years, $41.93 \%$ in $36-60$ years of age groups and $24.72 \%$ of growth in age $>60$ years. 
Table.1 Location wise isolation of Acinetobacter species ( $\mathrm{n}=190)$

\begin{tabular}{|l|c|c|}
\hline Location & Isolation & Percentage \\
\hline Out patient & 13 & $6.8 \%$ \\
\hline In patient & 177 & $93.2 \%$ \\
\hline Total & 190 & 100 \\
\hline
\end{tabular}

Table.2 Inpatient Distribution of Isolation of Acinetobacter species ( $\mathrm{N}=177)$

\begin{tabular}{|l|c|c|}
\hline \multicolumn{1}{|c|}{ Ward } & Isolation & Percentage \\
\hline ICU & 91 & 51.41 \\
\hline Medicine & 23 & 12.99 \\
\hline Neuro Surgery & 21 & 11.86 \\
\hline Surgery & 19 & 10.73 \\
\hline Orthopedics & 10 & 5.64 \\
\hline CVTS & 6 & 3.38 \\
\hline Others & 7 & 3.95 \\
\hline Total & 177 & 100 \\
\hline
\end{tabular}

Table.3 Clinical specimens showing isolation rates from different clinical samples

\begin{tabular}{|l|}
\hline Types of samples \\
\hline Endrotracheal tube \\
\hline Sputum \\
\hline Pus \\
\hline Blood \\
\hline Suction Catheter tip \\
\hline Tracheostomy tube \\
\hline Urine \\
\hline Tissue \\
\hline Foley's catheter tip \\
\hline Swab from suture site \\
\hline Others \\
\hline Total \\
\hline
\end{tabular}

\begin{tabular}{|c|c|}
\hline Isolates of Acinetobacter & Percentage \\
\hline 64 & 33.68 \\
\hline 26 & 13.68 \\
\hline 25 & 13.15 \\
\hline 20 & 10.52 \\
\hline 13 & 6.84 \\
\hline 11 & 5.78 \\
\hline 8 & 3.68 \\
\hline 4 & 4.21 \\
\hline 4 & 2.10 \\
\hline 8 & 2.10 \\
\hline 190 & 4.21 \\
\hline
\end{tabular}

Table.4 Age wise isolation of Acinetobacter baumannii

\begin{tabular}{|c|}
\hline Age group \\
\hline $0-1$ \\
\hline $2-10$ \\
\hline $11-20$ \\
\hline $21-30$ \\
\hline $31-40$ \\
\hline $41-50$ \\
\hline $51-60$ \\
\hline$>60$ \\
\hline
\end{tabular}

\begin{tabular}{|c|c|}
\hline Isolation & Percentage \\
\hline 23 & 12.10 \\
\hline 4 & 2.10 \\
\hline 10 & 5.26 \\
\hline 33 & 17.36 \\
\hline 27 & 14.21 \\
\hline 20 & 10.52 \\
\hline 18 & 9.47 \\
\hline 55 & 28.94 \\
\hline
\end{tabular}


Table.5 Antibiotic resistance pattern

\begin{tabular}{|c|c|c|c|c|c|}
\hline Name of Antibiotics & $\begin{array}{c}\text { Conc } \\
\text { (mcg) }\end{array}$ & $\begin{array}{c}\text { Resistance in } \\
\text { Hospitalized } \\
\quad(n=177)\end{array}$ & $\begin{array}{c}\text { Resistance in } \\
\text { non- } \\
\text { Hospitalized } \\
(\mathbf{n}=13)\end{array}$ & $\begin{array}{c}\text { Resistance in } \\
\text { Hospitalized } \\
(\%)\end{array}$ & $\begin{array}{c}\text { Resistance in } \\
\text { non- } \\
\text { Hospitalized } \\
(\%)\end{array}$ \\
\hline Amikacin (AK) & 30 & 136 & 02 & 76.83 & 15.38 \\
\hline Ciprofloxacin (CIP) & 05 & 125 & 04 & 70.62 & 30.76 \\
\hline Ceftotaxime (CTX) & 30 & 148 & 06 & 83.61 & 46.15 \\
\hline Cefuroxime (CXM) & 30 & 164 & 07 & 92.65 & 53.84 \\
\hline Augmentin (AMC) & 30 & 168 & 07 & 94.91 & 53.84 \\
\hline $\begin{array}{l}\text { Lomefloxacin } \\
\text { (LOM) }\end{array}$ & 30 & 123 & 03 & 69.49 & 33.33 \\
\hline Ceftazidime (CAZ) & 30 & 157 & 04 & 88.70 & 30.76 \\
\hline Cefeperazone (CPZ) & 75 & 145 & 03 & 81.92 & 23.07 \\
\hline Gentamicin (GEN) & 10 & 138 & 03 & 78.37 & 23.07 \\
\hline Neticillin (NET) & 30 & 76 & 01 & 42.93 & 7.69 \\
\hline Perfloxacin (PF) & 5 & 95 & 00 & 53.67 & 00 \\
\hline Ofloxacin (OF) & 5 & 35 & 00 & 19.77 & 00 \\
\hline Imipenem (I) & 10 & 107 & 00 & 60.45 & 00 \\
\hline Meropenem (MRP) & 10 & 117 & 01 & 66.10 & 7.69 \\
\hline Cefepime (CPM) & 30 & 158 & 02 & 89.26 & 15.38 \\
\hline $\begin{array}{l}\text { Ticarcillin + } \\
\text { Clavulanic acid } \\
\text { (TCC) }\end{array}$ & $75 / 10$ & 145 & 01 & 81.92 & 7.69 \\
\hline $\begin{array}{l}\text { Piperacillin + } \\
\text { Tazobactam (PIT) }\end{array}$ & $100 / 10$ & 156 & 02 & 88.13 & 15.38 \\
\hline Ceftriaxone (CTR) & 30 & 167 & 02 & 94.35 & 15.38 \\
\hline $\begin{array}{l}\text { Cefoperazone + } \\
\text { Sulbactum (CFS) }\end{array}$ & $50 / 50$ & 161 & 01 & 90.96 & 7.69 \\
\hline
\end{tabular}

Table.6 Percentage of MDR in Hospitalized and Non- Hospitalized patients

\begin{tabular}{|c|c|c|c|}
\hline Total no of ACB & $\begin{array}{c}\text { MIDR ACB in } \\
\text { Hospitalized }(\mathbf{n}=\mathbf{1 7 7})\end{array}$ & $\begin{array}{c}\text { MIDR ACB in non- } \\
\text { Hospitalized (n=13) }\end{array}$ & Percentage (\%) \\
\hline 190 & $\mathbf{1 4 2}$ & $\mathbf{0}$ & $\mathbf{7 5 \%}$ \\
\hline
\end{tabular}

Table.7 Incidence of Carbapenem-resistant Acinetobacter baumannii among Acinetobacter baumannii isolates

\begin{tabular}{|c|c|c|}
\hline Total ACB & $\begin{array}{c}\text { Carbapenem -resistant } \\
\text { Acinetobacter baumannii (CRAB) }\end{array}$ & Percentage (\%) \\
\hline 190 & $\mathbf{1 2 0}$ & $\mathbf{6 3 \%}$ \\
\hline
\end{tabular}


Table.8 Incidence of MBL production amongst CRAB (Carbapenem-resistant Acinetobacter baumannii) by Modified Hodge Test (MHT)

\begin{tabular}{|c|c|c|}
\hline Carbapenem -resistant & MIBL Producers & Percentage $(\%)$ \\
\hline Acinetobacter baumannii (CRAB) & By MHT & $\mathbf{5 3 \%}$ \\
\hline 120 & $\mathbf{6 3}$ & \\
\hline
\end{tabular}

Table.9 Comparison of the clinical specimens yielding ACB isolates among various series

\begin{tabular}{|c|l|l|l|l|}
\hline Sample & $\begin{array}{l}\text { Present } \\
\text { study }\end{array}$ & $\begin{array}{l}\text { Peymani } \text { et al., } \\
(\mathbf{2 0 1 1})\end{array}$ & $\begin{array}{l}\text { Mindolli } \text { et al., } \\
(\mathbf{2 0 1 0})\end{array}$ & $\begin{array}{l}\text { Dent } \text { et al., } \\
(\mathbf{2 0 1 0})\end{array}$ \\
\hline ET tube & $34 \%$ & $37 \%$ & $3.5 \%$ & - \\
\hline Urine & $5 \%$ & $21 \%$ & $28 \%$ & $16 \%$ \\
\hline Sputum & $14 \%$ & $9 \%$ & $25 \%$ & $31 \%$ \\
\hline Blood & $10 \%$ & $7 \%$ & $14 \%$ & $10 \%$ \\
\hline Pus & $13 \%$ & $8 \%$ & $29 \%$ & $13 \%$ \\
\hline Body fluids & $4 \%$ & $6 \%$ & $0.5 \%$ & - \\
\hline $\begin{array}{r}\text { Catheter } \\
\text { tips }\end{array}$ & $2 \%$ & $6 \%$ & - & $9 \%$ \\
\hline
\end{tabular}

Photograph.1 Growth of ACB on MacConkey agar

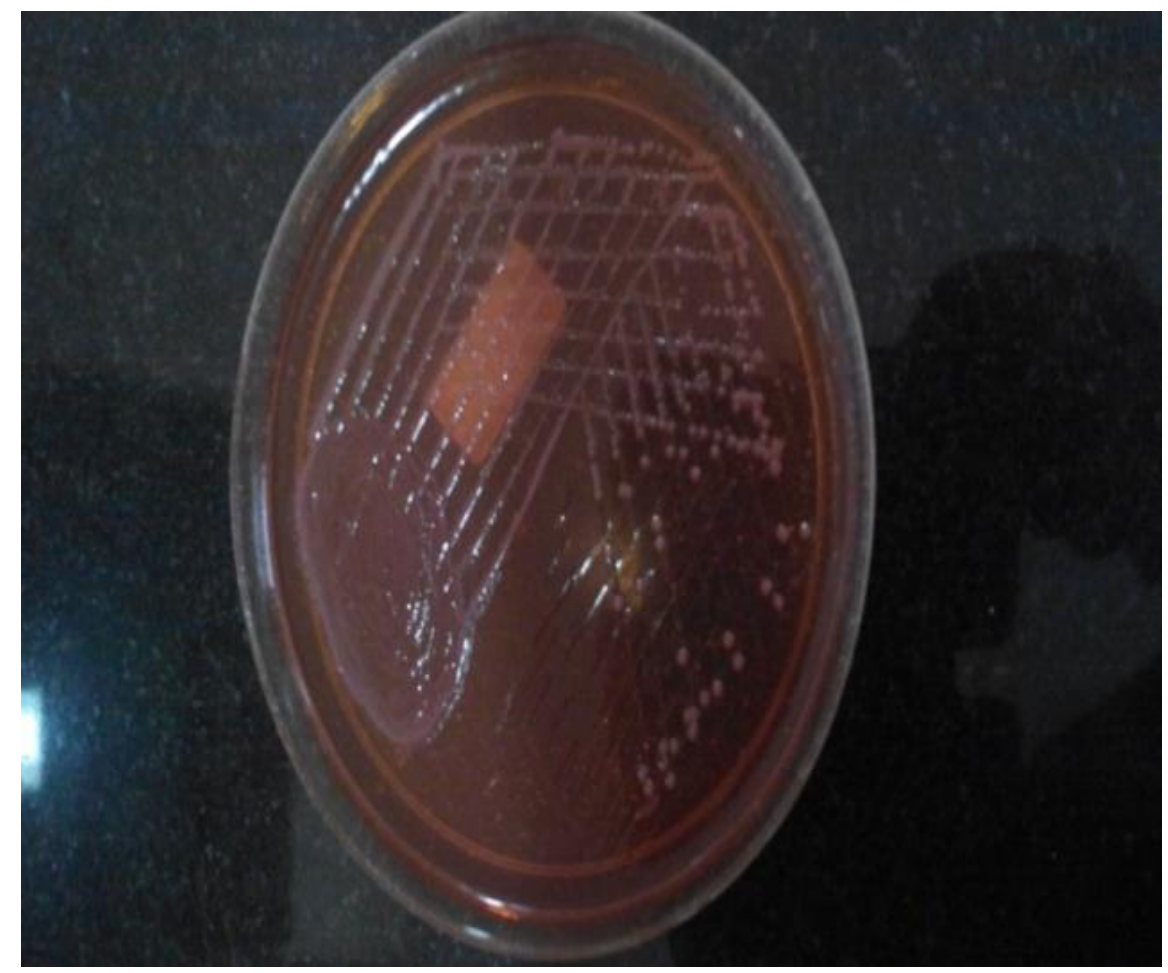


Photograph.2 Kirby Bauer Disc Diffusion Test

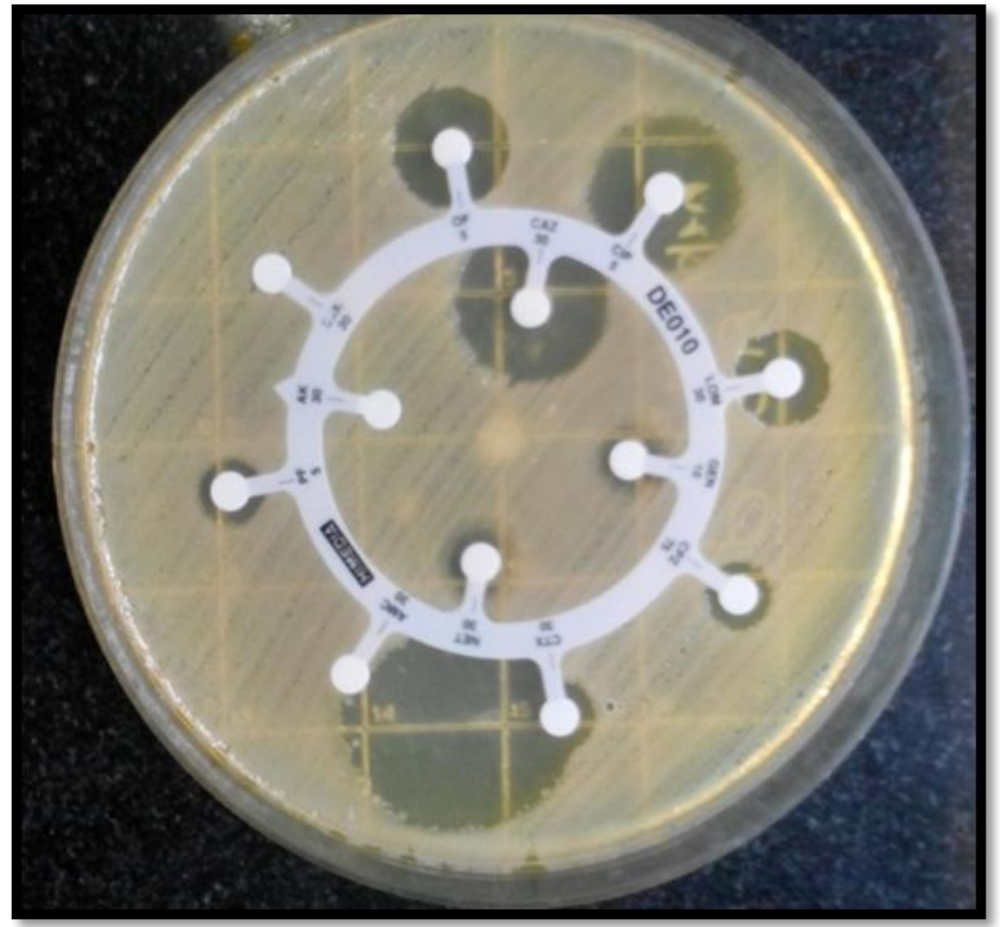

Photograph.3 Modified Hodge Test

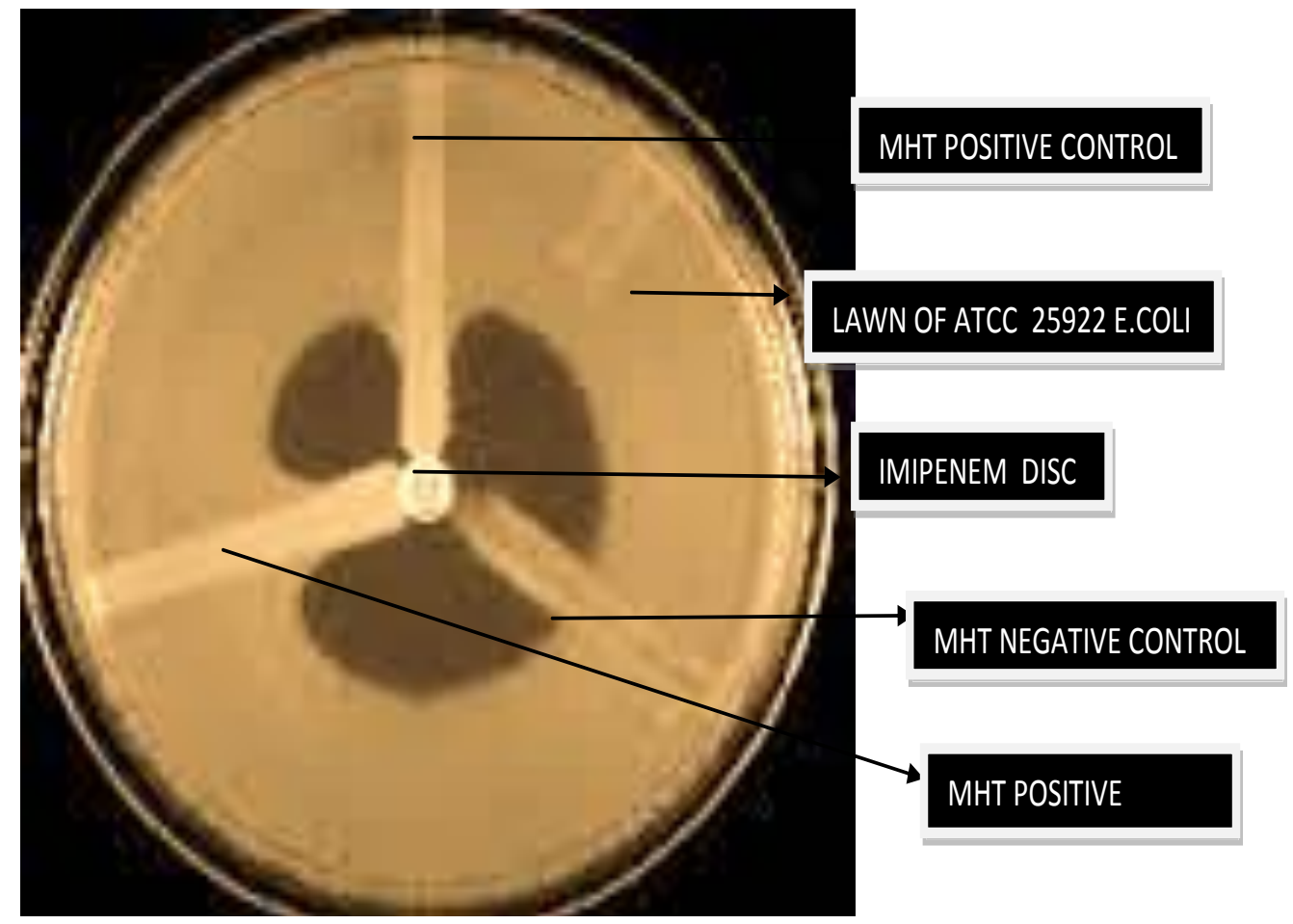


Fig.1 Pie chart showing the distribution of ACB isolates between in-patients and out-patients

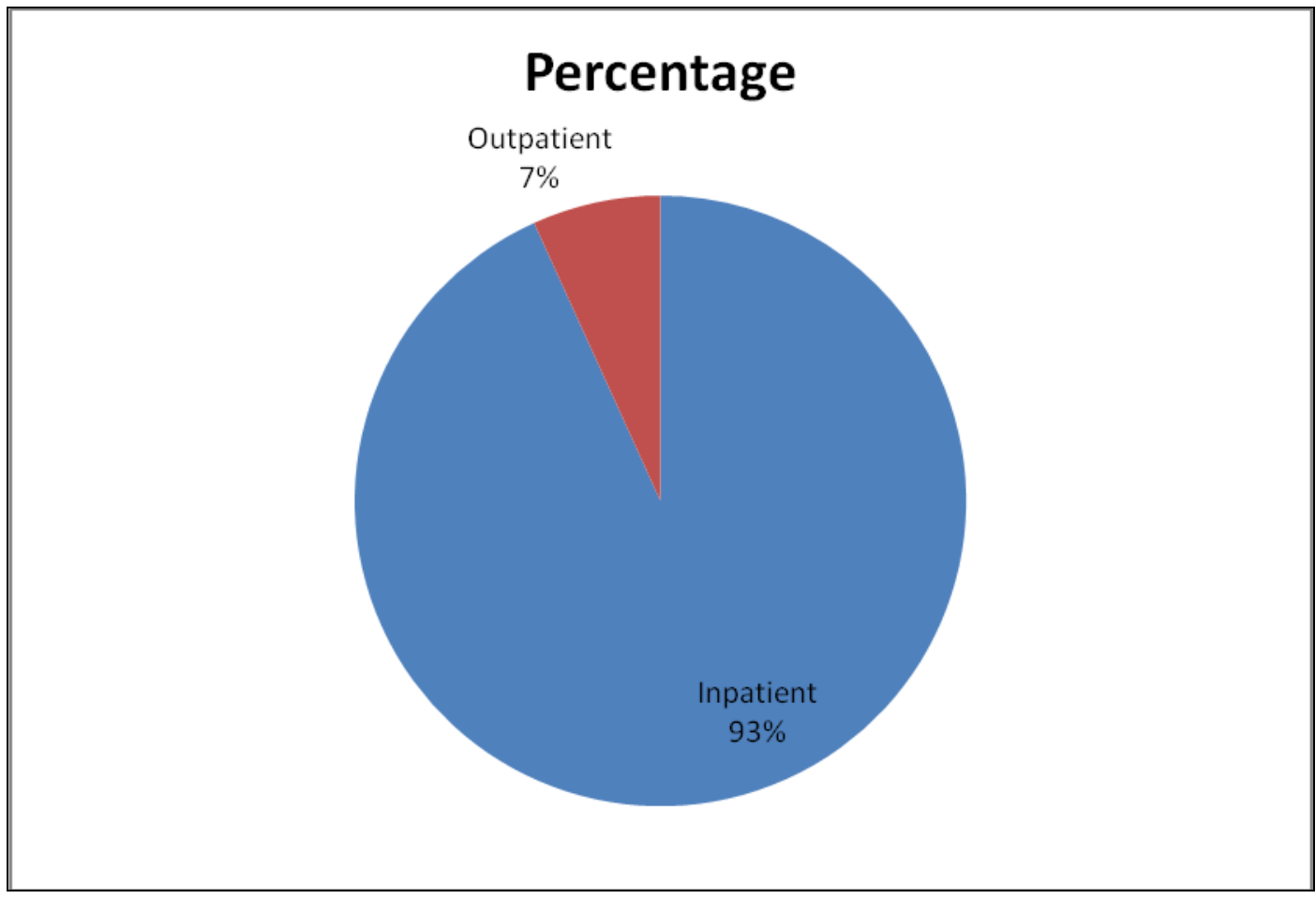

Fig.2 Pie chart showing the distribution of ACB isolates in various wards and ICU

\section{Percentage}

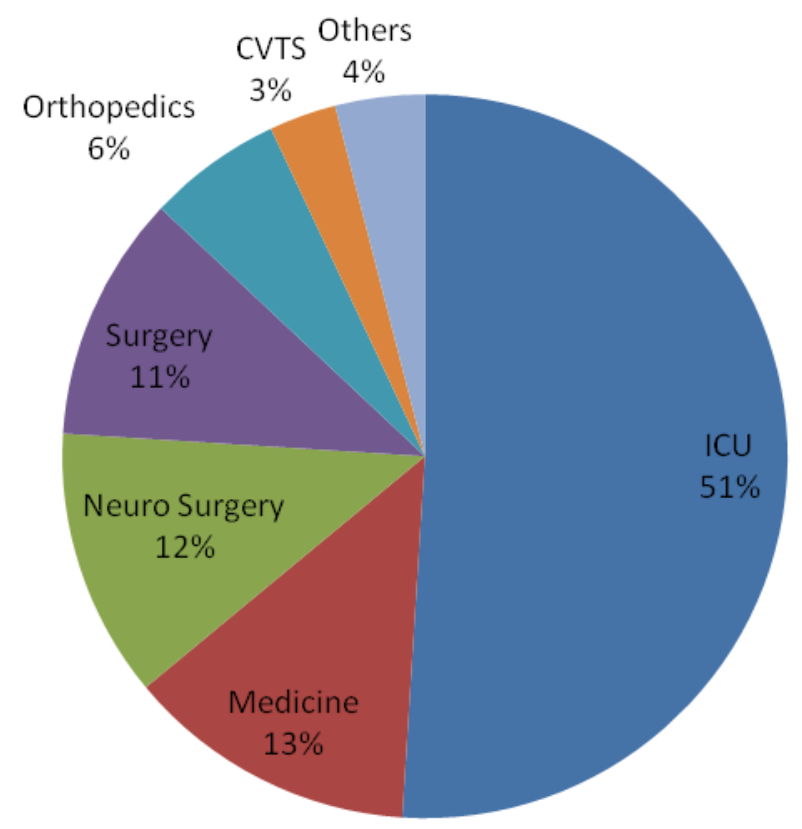


Fig.3 Pie chart showing the ACB isolates from various clinical specimens

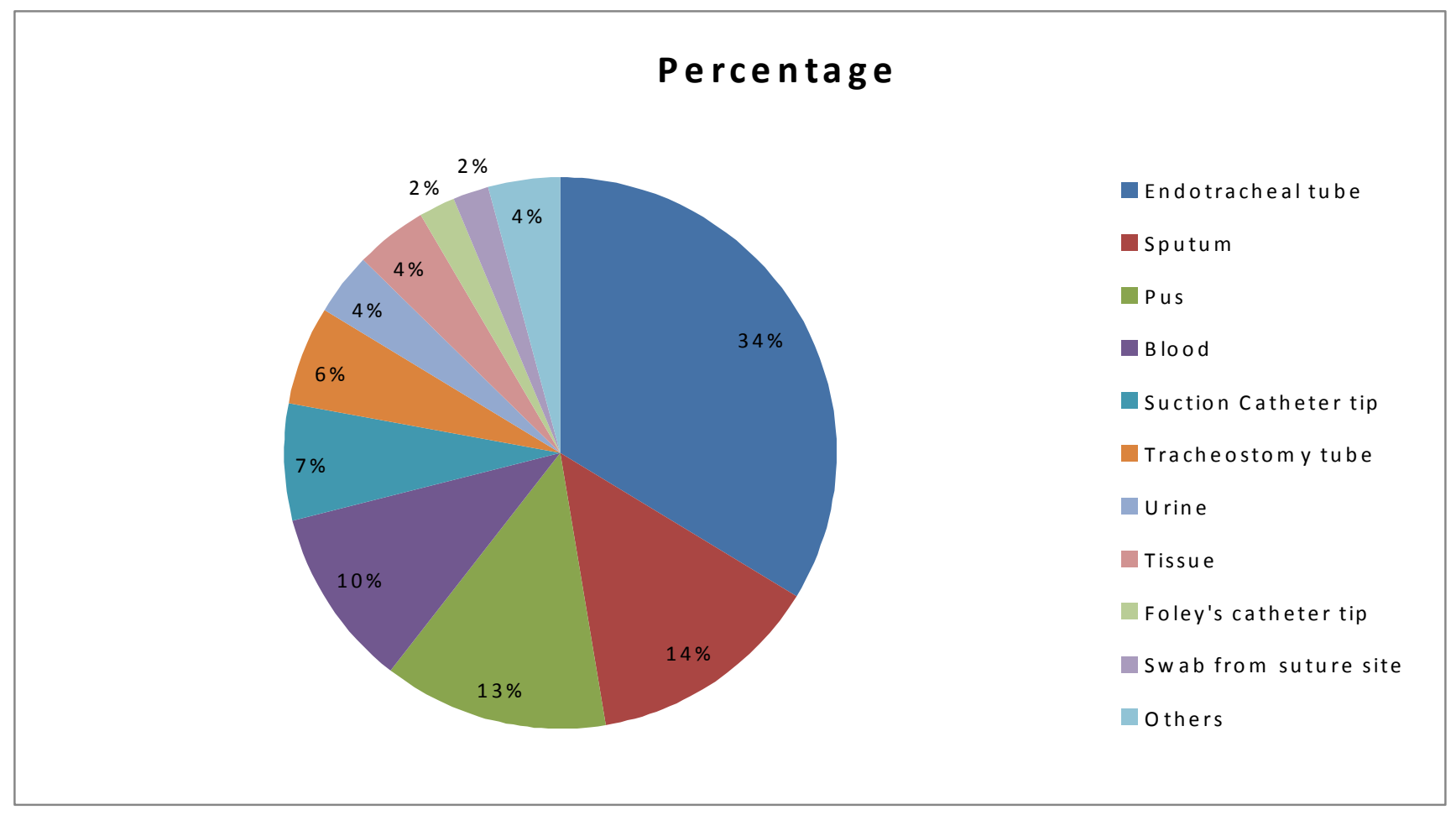

In contrast, the study done by Prashanth and Badrinath (2006), showed $60.47 \%$ isolates of Acinetobacter in age > 40 years and $39.53 \%$ in age $<40$ years, which is comparable with findings of our study.

In our study, Acinetobacter showed high degree of resistance $(>80 \%)$ to Cephalosporins (90\% to cefuroxime, $84.73 \%$ to ceftazidime, $81 \%$ to cefotaxime, $77.89 \%$ to cefaperazone), to piperacillin + tazobactum $(83 \%)$, to gentamicin $(74.21 \%)$, and to netillin $(40.52 \%)$ and least resistance to fluroquinolones, which included $18.42 \%$ to ofloxacin and $50 \%$ to perfloxacin. The organism was found to be highly resistant to Carbapenems (56.31\% resistant to imipenem and $62.10 \%$ resistant to meropenem) (Table 5). This is different from findings of Mindolli, PB et al., (2010) which showed lowest resistance to Carbapenems (9.5\%) and piperacillin + tazobactum $(9.5 \%)$ and high resistance to Ofloxacin (73.5\%). Jaggi et al.,
(2012), showed findings similar to our study. More than $85 \%$ isolates were resistant to cephalosporins, $90 \%$ resistant to piperacillin + tazobactum and $89 \%$ resistant to carbapenems. Muthusamy and Boppe (2012) found $100 \%$ resistance to carbapenems and 99\% resistance to cephalosporins. Peymani et al., (2011) found that the resistance to Piperacillin+tazobactum was $89 \%$, Ticarcillin+clavulanic acid $83 \%$, Augmentin $89 \%$, Ceftazidime $92 \%$, Cefepime $88 \%$, Ceftriaxone 94\%, Meropenem 56\%, Imipenem 54\%, Gentamicin 86\%, Amikacin $81 \%$ and Ciprofloxacin $86 \%$. These findings were similar to the results of our study. This shows that the extensive use of carbapenems has created a selective antibiotics pressure which in turn has resulted in increased prevalence of carbapenems resistant Acinetobacter baumannii (CRAB).

Our study found that $63 \%$ of $\mathrm{ACB}$ isolates were $\mathrm{CRAB}$ strains out of which $53 \%$ were 
MBL producers. Amudhan et al., (2011) have found that out of a total of 116 consecutive, non-duplicate carbapenems resistant $A$. baumannii isolates from various clinical specimens 113 (97\%) were MBL producers. Niranjan, DK. et al., (2013), reported that out of a total of 30 imipenem resistant, consecutive non-repeat clinical isolates of $A$. baumannii at a tertiary hospital in Delhi, all but one were MBL producer, as identified by the modified Hodge test (MHT). Khajuria et al., (2014), have found MBL producers to be $60 \%$ (using the MHT) in their 368 isolates, which included 155 (42.11\%) with reduced susceptibility to imipenem (Fig. 1-3; Table 69).

A. baumannii accounts for a substantial proportion of endemic nosocomial infections. Multidrug resistance is being increasingly reported in these pathogens and posing a threat to hospitalized patients due to the limitation of therapeutic options. The acquisition of multidrug resistance is related to environmental contamination and contact with transiently colonized health care providers. Carbapenems have been the drug of choice for treatment of infections caused by $A$. baumannii. However, in recent years, the number of isolates showing resistance to carbapenems has increased worldwide. This is mediated by the lack of drug penetration (i.e. porin mutations and efflux pumps) and/or carbapenem-hydrolyzing beta-lactamase enzymes such as OXA carbapenamases and metallo-beta-lactamases.

There is high incidence of multi-drug resistance seen in Acinetobacter calcoaceticus baumannii (ACB) isolates acquired from samples of hospitalized patients. Modified Hodge test, which is easy to carry out and not a very expensive one, can be included in routine testing for detection of $\mathrm{MBL}$ phenotypes. This will go a long way in early detection and help control infections due to this highly resistant organism.

\section{References}

Amudhan, S.M., Sekar, U., Arunagiri, K. and Sekar, B. 2011.OXA beta-lactamase mediated carbapenem resistance in Acinetobacter baumannii. Indian $\mathrm{J}$ Med Microbiol., 29:269-74.

Calfee D, Jenkins SG. 2008. Use of active surveillance cultures to detect asymptomatic colonization with carbapenem-resistant Klebsiella pneumoniae in intensive care unit patients. Infect Control Hosp Epidemiol., 29(10): 966-968.

CDC-Center of disease control: Modified Hodge test.

Chastre, J., Trouillet, J.L. 2000. Problem pathogens (Pseudomonas aeruginosa and Acinetobacter). Semin Respir Infect., 15(4): 287-298.

Dent, L.L., Marshall, D.R., Pratap, S., Hulette, R.B. 2010. Multidrug resistant Acinetobacter baumanii: A descriptive study in a city hospital. BMC Infect Dis., 10: 196-202.

Deshpande, L.M., Jones, R.N., Fritsche, T.R., Sader, H.S. 2006. Occurrence and characterization of carbapenemases produced by Enterobacteriaceae: report from the SENTRY Antimicrobial Surveillance Program (2000-2004). Microb. Drug Resist.,12(4): 223-230.

Gomty Mahajan, Jaspal Kaur, Shashi Chopra, Sheevani, Kapil Bhalla, Vineet Mahajan. 2012. Evaluation of clinical and prognostic factors associated with nosocomial Acinetobacter infection. AJPHS, vol 2(4): 572-576.

Jaggi, N., Sissodia, P., Sharma, L. 2012. Acinetobacter baumannii isolates in a tertiary care hospital: Antimicrobial resistance and clinical significance. Journal of Microbiology and Infect. Dis., 2(2): 5763.

Khajuria, A., Praharaj, A.K., Kumar, M., Grover, N. 2014. Molecular Characterization of Carbapenem Resistant Isolates of Acinetobacter baumannii in An Intensive Care Unit of A Tertiary Care Centre at 
Central India. J Clin Diag Res., 8(5): DC38-DC40.

Lahiri, K.K., Mani, N.S., Purai, S.S. 2004. Acinetobacter spp. As nosocomial pathogens: Clinical significance and antimicrobial sensitivity. Med J Armed Forces India, 60: 7-10.

Livermore, D.M. 2002. The impact of carbapenemases on antimicrobial development and therapy. Curr Opin Investig Drugs., 3(2): 218-224.

Mindolli, P.B., Salmani, M.P., Vishwanath, G., Hanumanthappa, A.R. 2010. Identification and speciation of Acinetobacter and their antimicrobial susceptibility testing. Al Ameen J Med Sci., 3(4): 345-49.

Muthusamy, D., Boppe, A. 2012. Methods for the detection of various beta-lactamases in carbapenem resistant isolates of Acinetobacter baumanii at a tertiary care hospital in South India. J Clin Diag Res., 6(6): 970-973.

Niranjan, D.K., Singh, N.P., Manchanda, V., Rai, S., Kaur, I.R. 2013. Multiple carbapenem hydrolyzing genes in clinical isolates of Acinetobacter baumannii. Indian J Med Microbiol., 31(3): 237-241.

Noyal, M.J., Menezes, G.A., Harish, B.N., Sujatha, S., Parija, S.C. 2009. Simple screening tests for detection of carbapenemases in clinical isolates of nonfermentative gram-negative bacteria. Indian J Med Res.,129:707-12.

Peymani, A., Nahaei, M.R., Farajnia, S., Hasani, A., Mirsalehian, A., Sohrabi, N., et al., 2011. High prevalence of metallo-betalactamase-producing Acinetobacter baumannii in a teaching hospital in Tabriz, Iran. Jpn J Infect Dis.,64 (1):69-71.
Prashanth, K., Badrinath, S. 2006. Nosocomial infections due to Acinetobacter species: Clinical findings, risk and prognostic factors. Indian J Med Microbiol.,24: 39-44.

Schreckenberger, P.C., Von Graevenitz, (1999). Acinetobacter, Achromobacter, Alcaligenes, Moraxella, Methylobacterium, and other nonfermentative gram-negative rods in Manual of clinical microbiology, eds Murray P. R., Baron E. J., Pfaller M. A., Tenover F. C., Yolken R. H. (ASM Press, Washington, D.C.) 7th ed. pp 539560.

Siegel, J.D., Rhinehart, E., Jackson, M., Chiarello, L. and Healthcare Infection Control Practices Advisory Committee. 2007. Management of multidrug-resistant organisms in health care settings, 2006. Am J Infect Control.,35(10):(S165-S193)

Simor, A.E., Lee, M., Vearncombe, M., JonesPaul, L., Barry, C., Gomez, M., Fish, J.S., Cartotto, R.C., Palmer, R., Louie, M. 2002. An outbreak due to multiresistant Acinetobacter baumannii in a burn unit: risk factors for acquisition and management. Infect Control Hosp Epidemiol., 23(5): 261-267.

Wayne, P.A. 2009. Clinical and Laboratory Standards Institute/NCCLS. Performance Standards for Antimicrobial Susceptibility Testing. M100-S19. CLSI.

Yong, D., Shin, J.H., Kim, S., Lim, Y., Yum, J.H., Lee, K., Chong, Y., Bauernfeind, A. 2003. High prevalence of PER-1 extendedspectrum $\beta$-lactamase-producing Acinetobacter spp in Korea. Antimicrob Agents Chemother., 47(5):1749-1751.

\section{How to cite this article:}

Amrita Talukdar, Anahita Bhesania Hodiwala and Revati Sharma. 2018. A Microbiological Study of Acinetobacter baumannii with Special Reference to Multi-Drug Resistance. Int.J.Curr.Microbiol.App.Sci. 7(02): 1176-1186. doi: https://doi.org/10.20546/ijcmas.2018.702.145 